Comparative Philosophy Volume 12, No. 1 (2021): 209-214

Open Access / ISSN 2151-6014 / www.comparativephilosophy.org

https://doi.org/10.31979/2151-6014(2021).120116

\title{
RECENT WORK
}

\author{
BOOK REVIEW ON \\ NEW ESSAY IN JAPANEE AESTHETICS \\ (EDITED BY A. MINH NGUYEN)*
}

MARY WISEMAN

This anthology takes us to places Western aesthetics never dreams to go, to taking tea, wrapping boxes, going to war, and seeing martial art as a moral discipline. The conglomeration of articles reflects the complexity and contradictoriness of Japanese history and culture. There is little here on contemporary Japanese modern art, but this is clearly outside the ambitious brief of its editor. The countries of the world, newly bound by the coronavirus have, I would say, an obligation to get to know each other, and this book helps us get to know Japan by giving us a sense of the breadth and depth of its culture.

In this review I am going, first, to claim that aesthetics has become global and, therefore, the book under review is important and welcome to Western readers and, second, after some general observations about the shape and tenor of the book, to take a close look at several essays. As readers of this journal know, Japanese aesthetics is significantly different from Western aesthetics, in part because many of the questions explored in Western aesthetics are abstract: what is a work of art, wherein does its value lie, what are aesthetic properties, aesthetic experiences, what is the status of the artist's intention and the role of the audience? True, the field is changing in the West as increasing attention is paid to an artwork's other-than-aesthetic dimensions, the ethical, neuroscientific, perceptual, and political among them, and to the digital and popular arts, while interest in the aesthetic is no longer confined to its role in works of art. Attention extends to its role in the world of everyday and the natural world. Many of these changes bring it closer to Japanese aesthetics, whose focus extends to the whole of the everyday world, to virtually everything that people do. Western aesthetics is, even so, significantly different from its Japanese counterpart, which exquisitely

WISEMAN, MARY BITTNER: Professor of Philosophy Emerita, Brooklyn College and the CUNY Graduate Center, USA. Email: marigold21@comcast.net

* A. Minh Nguyen (ed.) (2017), New Essays in Japanese Aesthetics (Lanham: Lexington Books), lxxv+520 pps. ISBN 978-0739180815 (2019 paperback ISBN 978-1498572118) 
describes, rather than analyzes, the concepts with which it works. They are concepts of what experience reveals, and they beggar translation into English, concepts such as wabi, transient and austere beauty, sabi, rustic patina and aging, mono no aware, the pathos of things. Appreciation rather than analysis is the glory of Japanese aesthetics.

Some essays in New Essays in Japanese Aesthetics reflect a tension between the local and the global or as it is put in "The Idea of Greece in Modern Japan's Cultural Dreams," between what is distinctive about Japanese aesthetics and what gives it a place on the world stage, with the implication that the one precludes the other. This reprises a debate that arose in the wake of New York Museum of Modern Art's 1984 exhibition 'Primitivism' in 20th Century Art: Affinity of the Tribal and the Modern when the critic Thomas McEviilley staunchly attacked the thesis of the exhibition that we can appreciate primitive art only because of its formal affinity with modern art. He is said to have launched multiculturalism with his articles that began to toll the death knell of the hegemony of Western art. McEvilley's claim was that the primitive works, out of their tribal context as they were when exhibited in vitrines in MoMA, absent the blood and mud of the ceremonies for which they were intended, were shorn of their identity. He called the exhibition the last cry of a dying modernism as he insisted on the relevance of a work's myriad contexts. He celebrated the difference between the primitive and the modern, but claimed, contrary to the MoMA curators, William Rubin and Kurt Varnadoe, that we are able to imagine the tribal ceremonies and so to appreciate the works for what they are rather than for such affinity as they have with Western modern art.

Jean-Hubert Martin, curator of the influential 1989 Pompidou Center's Les Magiociens de la Terre, 50\% of whose artists were Western and 50\% non-Western, each non-Western artist identified by name and regarded as a peer of the Western artists, said that it was McEvilley's articles that inspired the exhibition. The nonWestern was no longer treated as the Other, and the art world was on its way to becoming polycentric, that is to say, global. Another exhibition, the Guggenheim Museum's 2017 Art and China after 1989: The Theater of the World, furthers the tale and is as relevant to the Japanese art world as it is to the Chinese. Alexandra Munroe, one of the curators, took 1989 as the year when art became global, claiming that the new art from China was no longer be part of a Sino-centric narrative, but of a global one. A critic of the exhibition said both that the work shown was clearly Chinese and so was Sino-centric and that so many of the artists lived outside of China that they hardly represented Chinese art. To this second objection the answer is that many of the Chinese expat artists said they became most aware of their Chinese-ness once they left China. In the same vein, the Japanese philosopher and poet, Kuki Shugo, said that living in Europe for seven years allowed him to see clearly for the first time the beauty of Japan/s culture. The answer to the first objection is that the Chinese art after 1989 is of interest to the rest of the world precisely because it is different, because of what is distinctively Chinese about it, allowing that there are various ways of something's being distinctively of its place.

Because aesthetics reveals full as much, if not more, of the ethos of a place than does its art, one way to grasp the conceptual geography of a culture is look at the role 
aesthetics plays in it. Such worry as there is about a tension between what is distinctively Japanese about its aesthetics and what gives it a place in the world is laid to rest. Modernism's conceit that form is significant because it taps into something shared and understood by everyone, "the child, the savage, the metaphysician," as Le Corbusier said in his Vers une Architecture (1923). Not only does significant form make of an object a work of art, but it also gives art its universal appeal. It is important to see that this is not the same as global appeal, for the globe contains myriad continents, countries, cultures, all different in some way and to some degree. The suspicion that form is not the only thing that gives aesthetic pleasure and has aesthetic value, whether the object is a work of art or the ripple in a stream, is a conceit of postmodernism, which celebrates content, context, and difference, not sameness. Turn now to New Essays in Japanese Aesthetics, rich as it is in content, contexts, and difference.

After a forward and two introductory essays, the book divides into six parts, whose subjects become increasingly narrow. The first five are entitled "Japanese Aesthetics and ...", the topics of the first three are general: philosophy, culture, and cultural politics. The topics of the second two sections are particular arts, literature and the visual arts, while that of the third is one person, Kuki Shuzo (1888-1941), who studied with Husserl, Heidegger, Henri Bergson, and Sartre. His best-known book is The Structure of "Iki" (1930), where iki is a property of objects or a state of mind. Because it is not practical to review the book's 27 essays, I am going to list not titles but words and phrases from some titles to show the breadth of the essays' subjects. The number of the essay appears in brackets after the phrases: the aesthetics of the indistinct (3), ecstasy as beauty in ... Schopenhauer (4), the appreciative paradox of Japanese gardens (7), appreciating food in Japan (8), the art of war ... aesthetic cultivation in Japanese martial arts (9), the idea of Greece (11), aestheticizing sacrifice ... during the Asia-Pacific was (13), the aesthetics of urban strolling (14), aesthetic experience in post- atomic Japanese narrative (19), the aesthetics of disaster (20), the aesthetics of emptiness ... and abstract expressionism (23), olfactory aesthetics (27).

Look now at the first and last essays in the book. The first is Yuriko Saito's introductory "Historical Overview of Japanese Aesthetics," and the last is Peter Leech's "Scents and Sensibility: Kuki Shuzo and Olfactory Aesthetics." Saito begins with reference to an indigenous Japanese aesthetic tradition that persists into the present. That she uses "indigenous" rather than "traditional" shows how close to the bone and far from the halls of academic this aesthetics is. Themes that have persisted are, first, what she calls aesthetic particularism, which is not only that aesthetics affects every aspect of human lives, but also that it involves all of the senses. The second common theme is that of implication, suggestion, and imperfection. The implied virtues of indirection, the obscure, the hidden, the defective have a history that began in the Heian Period (794-1150) as an art of seduction among the aristocrats, for example, the sight of a woman so veiled as to expose only the bottom of an exquisite kimono would fire the imagination of what other beauties were there to be seen. These virtues were adopted by the samurai, an inherited warrior class that arose from common stock, after the Heian Period and eventually filtered down to everyone. Saito observes that the attraction of the hidden, for example, the moon obscured by mist, is parasitic on 
knowing what the moon is like when seen in full. The invitation is to imagine for oneself what is hidden. As Roland Barthes put it, the erotic is where the garment gapes.

Another virtue that appears as a common theme is imperfection. There is the kind that time brings - the patina on old wood or something's having been worn away by use - and is a sign of the impermanence of all things, a Zen theme. But there is another kind that is unavoidable by the poor, the torn, the chipped, the broken, the worn out. Saito notes that valuing imperfection might be seen as aestheticizing it, which in turn, could be either a way of coping with poverty or a recognition and acceptance of the fact that things just do tear and chip and break. There is wisdom in the acceptance of the broken, but denial in the aestheticization of poverty, which is to make of it something to be appreciated and valued. Unless one has chosen that life, the poor are not likely to appreciate or value their poverty. At the outset of her discussion of this second theme common to Japanese aesthetics, Saito describe three of the myriad hardto-translate properties through their presence in works of art. Her three are wabi, the beauty of poverty in the tea ceremony, sabi, the lonely beauty in haiku, and yugen, mystery and depth in NO theater. This section gives the reader a quintessentially Japanese view of the arts to which she refers.

The third common theme identified is respect for the essential characteristics of the object. This resonates with the wonder that anything whatsoever exists and the insistence of each thing that it does exist. This is captured by Gerard Manley Hopkins (1844-1889) in When Kingfishers Catch Fire where he says that each thing finds tongue to "fling out broad its name;/ Each mortal thing does one thing and the same:/ Deals out the being indoor each thing dwells." The theme of respecting objects appears also in The Lifegiving Joy of Tidying Up (2011) by Marie Kondo, who says that when going through one's belongings, one should take those that no longer bring joy, thank them for what they have given their owner, and give them away. At the same time that Saito gives secular histories of the appearance of certain values, she also details how the tenets of Zen Buddhism underly them. Zen Buddhism holds that all things are impermanent and that they are all replete with Buddha nature and so worthy of equal respect. Moreover, objects can be sad when their owners die, a sign of the interconnectedness and equality, even sameness, of people and things.

The fourth and final common theme raises questions. Saito describes it as "sincerity and devotion as criteria for intentionalist criticism" (xli). She starts with the West's intentional fallacy, the supposition that one must know what an artist intended in making a work in order to grasp its meaning. In Japanese aesthetics the inseparability of artist and artwork is assumed, and this, Saito argues, requires evaluation of a work to refer to an artist's state of mind. She continues that it is a legacy of Zen Buddhism that art-making be considered a way of enlightenment, which requires selftranscendence. The art of an artist who has transcended himself appears to be natural, spontaneous, and artless because it is free from "the conscious attempt to achieve artistic success" (xii). Saito calls this "intentionalist" on the ground that such an artist has no intentions. But since he has no mental attitudes or activities whatsoever, it is misleading to focus only on the absence of intentions. She goes on to talk of their being no separation between what the mind dictates and the hand executes, but, again, the 
mind of the artist who has transcended himself dictates nothing. The inseparability is between the person, whose senses are intelligent and mind embodied, and her work, between the dancer and her dance. At most one can say that when mind and hand work in concert they are one. However, this is a minor cavil about this stunning overview of Japanese history that ends with two short sections on recent scholarship and its challenges to Western aesthetics.

The other article I discuss. "Scents and Sensibility: Kuki Shugo and Olfactory Aesthetics," is as narrow as Saito's is broad. Narrow, even though it refers to Aristotle's square of oppositions, Euclid's axioms, and Kant on the synthetic a priori, the "primitive" sense of smell, and the sublime. Its thesis, bold and original, is that the olfactory is at the outer limits of an aesthetics rife with rules, as seen in the ceremonies of tea and of incense, but has, nonetheless, "a bolder presence in the phenomenology of Japanese aesthetics itself" than is realized (410). All the aspects of Kuki's life are in play in Leech's argument. Kuki studied Kant at the Tokyo Imperial University but left doctoral studies to go to France, from which he traveled to Germany to study extensively under Heidegger. Hence the phenomenological thrust of much of his work, including his The Structure of "Iki." When he went to Paris, where he also studied philosophy, he began to write many tankas, short five-line poems $(5,7,5,7,7$,$) . He was$ keenly aware of the perfumes the women wore, and he said he sprinkled his own vest with Guerlain's Bouquet des Faunes.

Leech begins with the scents of Kuki as they appear in his poems to show their prominence in his thought, lines such as: "A scent more fleeting then a dream" and "The old bookstores stand in a row,/ Letting the fragrance of the past flow," and, again, "Good,/ Smell the fragrance./ Evil,/ Let the flower bloom." This refers to Baudelaire's Fleurs du Mal (1857), between which and Kant there is a tension as seen in: "The Flowers of Evil and Kant's Critique of Pure Reason/ Stand shoulder to shoulder/ Leering at each other." Still reading the poems, Leech draws a line connecting smells, $i k i$, and Kant in "My heart smells/ A fragrance similar to/ To the [iki] of my homeland" and again "My heart says,/ Lately it hurts!/ After a while/ The soul says,/ Go back to Kant." The shape of the article and the argument are laid out.

First, Leech argues, contra Kant, that smells can be described. Then, he notes that the word $i k i$ and seven others that Kuki used in a diagram of the structure of $i k i$ in his book can be used to describe smells. Finally, reading the diagram in light of Aristotle's square of oppositions, Leech shows the words to stand in the relation of contradiction and in other relations shown in the square. Smells have a discursive dimension and so seem able to enter the realm of aesthetic judgment. Moving from the square of oppositions to Euclid's axiom about parallel lines gets us to Kant's synthetic a priori. Since there are non-Euclidean geometries, Reiman's the best known, in which either there are no parallel lines or there are and they meet in curved space, Euclid's axiom is not necessary and so is not properly an axiom.

But Kuki sees how counter-intuitive this is: "The principle that parallel lines do not intersect/ To the intersection of parallels don't you object?/ With this, contingency is fulfilled." The non-intersection of parallel lines may be contingent, but since we cannot help but object to their intersecting, their non-intersection is necessary. Kuki then went 
back to Kant, for is not Kant's synthetic a prior "contingency fulfilled?" Kant uses Euclid's proposition that the shortest distance between two points is a straight line to show what synthetic a priori is. The concept straight does not contain the idea of short, so the proposition is contingent, but it is taken to be necessary and hence, priori to experience. Kuki is trying to overcome the idea that aesthetic judgments are purely contingent. To show that this is so, Leech interpreted Kuki's diagram of the structure of $i k i$ in terms of the square of oppositions, which is a matter of logic, not experience. The trouble is that because aesthetic judgments are not based on rules they seem to be contingent. Back to Kant, who says there is: "no fine art in which something ... capable of being comprehended ... in obedience to rules ... does not constitute the essential condition of the art" (408), where this refers to the aesthetic rules that abound in the incense and the tea ceremonies and are ubiquitous in Japan from flower arranging to the wrapping of lunch boxes.

Even so, we seem able to get no cognitive purchase on our experience of smells because they overwhelm us. We are said "to swallow smells whole," and Leech suggests this experience of possession or envelopment is why Kant puts the olfactory is at the outer limit of the aesthetic. In an ingenious move, Leech reminds us that smell of the five senses is the one that "most nearly approaches the contingent condition of what Kant understood as the "sublime" (409) of which Kant says that it may seem "to contravene the ends of our power of judgment ....and to be, as it were, an outrage on the imagination" (408). So, Leech observes, does the olfactory. For this reason, Kant finds the olfactory to have no epistemic or aesthetic value. But not so Kuki, who claimed to have the smell of the Japanese past. The presence of smell is evident in the Japanese world. Although the Japanese find the wearing of scent a pollution, there is the tradition of the incense ceremony where one is said to "listen" to the fragrances of the incense, and there is also the habit of bringing a bowl of noodles to the nose to smell it and of slurping soup to heighten its smell. By interpreting Kuki's diagram of $i k i$ in olfactory terms, Leech surprises a structural logic in scents despite their fleeting nature. By going back to Kant, Leech sees Kuki as defying Kant's dismissal of smell and recovering it as a bona fide part of the Japanese aesthetics experience. Saito, with her aesthetic egalitarianism, would no doubt agree. 